\title{
The production of the subject in research training ${ }^{1}$
}

DOI: https://doi.org/10.32870/dse.v0i12.254

\section{Cristina Palomar Verea*}

(Trad. Moisés Silva)

\begin{abstract}
This paper is a reflection on the current and problematic situation of research training in Mexico, conducted through from daily work with graduate students in a public university. It argues that such training takes place without taking into account many of the difficulties faced by apprentices of the research craft because they have reached this educational level without having learned the basic skills and knowledge required, and because training programs disregard these difficulties and privilege the figure of the researcher instead of his/her work. These issues are explored through a brief inquiry centered on the students' viewpoints, followed by some of our conclusions. Keywords: subject, professional research training, research craft, research training device, ideal researcher.
\end{abstract}

I.

There seems to be widespread agreement in Mexico about the growing need and great importance of fostering the training of new researchers in higher education institutions (IES). This agreement seems to be sustained by an imagined link that is often too easily believed to exist between the number of researchers and a burgeoning development of the country. It is assumed that the greater the number of researchers is, the nearer the country will be to progress and the other Enlightenment goals. Nevertheless, such a link should not be taken from granted, since there are several factors in our country that make it problematic. Some of these factors are related both to the training process of new researchers and to the real possibilities that these researchers will have in the current Mexican environment to find positions where they can conduct scientific research and thus contribute to the country's development. On the other hand, it would be necessary to establish how relevant the product of scientific research may actually be to decisions having to do with national development.

Another assumption made in an optimistic assessment of the growth of research training programs in Mexico is that they are a means of fulfilling the goal of teaching students to do scientific research according to the universal rules and principles of science, as well as the international standards associated with them. These programs generate the subject of Mexico's science, whose

1 A shorter version of this paper was presented at the Seminar "Formando investigadores. Problemas y desafios" ["Training Researchers: Problems and Challenges"], held by the University of Guadalajara and Universidad Tres de Febrero in Guadalajara, Mexico, from November 25 to $28,2013$.

* Psychoanalist and Doctor in Social Sciences with a specialization in Social Anthropology. Research professor at the Departament for Education Studies of the University of Guadalajara. National Research Network (SNI) Researcher, Level II. E-mail: crispalvertina@hotmail.com 
"advent" is the result of the different discourses and knowledge that make up scientific training programs. What many research training programs state as an expected result ${ }^{1}$ is to produce human resources of a "high level", "with an level of excellence", "highly trained", "with high levels of quality and excellence", "highly qualified", or "with a high sense of achievement". These ways of characterizing the subject expected in these programs reveals two issues: first, that the programs are focused on producing a particular kind of individuals who fulfill such characterizations, and second, that the meaning of those descriptions -which seem to stem from the challenges that the domestic and international economy present to educational institutions in Mexico, combined with social and demographic pressures, political demands, budgetary anxieties, as well as cultural and educational changes- is far from clear. Latapí (2007) points out that such institutions

are demanded to produce quality and forced to modernize, be efficient, train the working forces that the market requires, develop an entrepreneurial culture, innovate in their pedagogical methods and management procedures, be evaluated and accredited on solid bases, and they are proposed an "information society" as a compulsory paradigm for the future: if knowledge is -and will increasingly be- a vertebral axis of globalized economies, it is the task of educational systems, and especially universities, to generate, provide and distribute that essential knowledge (Latapí, 2007: s/p).

In that context, the issues of excellence and quality in education acquire great importance, since they are akin to the requirements for any product aiming to compete in a global market (which is what "quality" researchers are expected to do). However, Latapí observes that there are no clear definitions of what is meant by "quality", although it is commonly mistaken for the learning of academic knowledge and obtaining good grades, but also associated with a certain notion of "success" in the job market. It is not clear either how "excellence" -a superlative- can be useful to understand what is expected of scientific training, which leads us to raise the question of how these expectations, which have more to do with the students as persons than with their education in research, play a role in the training of new researchers.

This paper is an inquiry into this problematic situation. It has also been nourished by concerns derived from day-to-day work with graduate students in a Mexican public university, which has given rise to a few questions: How, and through which paths, does one become a researcher? What is the training experience like? How can one define research based on that experience? How are research professors and thesis directors perceived in their role as central actors in research training, and what kind of relationship do students establish with them? What is the ideal kind of researcher produced in training programs?

1 These are some of the stated objectives that appear in research training graduate program websites of the National Autonomous University of Mexico (UNAM), as well as the University of Guadalajara, the Center for Research and Advanced Studies of the National Polytechnical Institute (CINVESTAV) and the Center for Research and Studies in Social Anthropology (CIESAS). Our review included the program objectives in the fields of the social sciences, mathematical sciences, social anthropology, communication, biomedical sciences, and education. 
We searched for answers to these questions through a simple study which started from the assertion that Mexico's graduate program system has, besides the explicit goal of training researchers, an unstated mission: to produce a subject for science through an overly demanding device that seeks not only to make up for or conceal the deficiencies in the country's educational system -from the elementary to the higher levels- but also to make the subject produced able to compete in an international stage of scientific work, as an embodiment of the expectations of quality and excellence proposed by the research training program objectives.

II.

How does someone become a researcher? Is it about vocation or destiny? Is it one's own project, or the result of a goal projected by others? The notion of science as a vocation is as old as scientific institutions themselves. Noble (1993) points out that at the origin of all scientific institutions there lies a common root: a desire for transcendence and for the sacred, which explains the ancient link between religious vocation and scientific vocation. Both demanded celibacy because both required total dedication from those who heeded the call of their vocation, which was the only thing that justified severing the ties of family and affection, regarded as distracting and weakening of the virility needed for such a high enterprise. ${ }^{2}$ In its dictionary of Spanish, the Royal Spanish Academy (RAE, online), acknowledges four definitions of vocation (vocación), all congruent with the link between religious life and scientific life: 1) an inspiration through which God calls towards a state, especially that of religion; 2) avocation; 3 ) inclination towards any state, profession, or career, and 4) appeal, call.

Ciporkin (2004) says that

etymologically, the word vocation comes from vocatio, the act of calling and the fact of being called. In Latin it had those meanings as a reflection of the verb voco, from which we get 'voice', 'evoke', 'convoke'. Under the influence of Christianity it acquired a specific meaning, which is applied in religious contexts. From that viewpoint, a vocation is a call through which God "inclines someone towards a state of life" (Ciporkin, 2004: s/p).

She also points out that the term "vocation" was used beyond the realm of the religious to refer to a "professional, artistic, scientific vocation, a certain attraction exerted by a particular object from which it is difficult to escape". She also highlights an underlying notion of "being called upon by God to fulfill a given mission [which] is an allusion to a subject who is chosen, and who by virtue of this choice will be destined to an accomplishment to has been assigned to him/her".

2 Based on such foundations, it was obviously not surprising that the symbolic principle guiding this field of work was the one associated with masculinity, since the domestic and family environment, regarded as the sphere of women and therefore feminine, was opposed to the ideals required for scientific vocation. 
Ciporkin argues that "vocation as a call can be located at the point where a subject attaches and links the name of a profession or task in a culture with his/her personal tasks".

In the early twentieth century, Weber distinguished the external conditions of academic life from the "inner vocation" that, at the time, was determined by a previously unknown specialization. He argued that "only a rigorous specialization will give a scientific worker the full comprehension of having achieved, perhaps for the first and last time in his life, something permanent" (Weber, 2006: 91), adding that

He who is unable to put on blinders and convince himself that his destiny hangs on making the right conjecture in this or that paragraph of this or that manuscript is not made for science. He will never feel in himself what we might call the "experience" of science. Without this intoxication, absurd for the layman, without this passion, without the sensation that "thousands of years had to pass so I could appear and put this hypothesis to the test", one does not have a vocation for science and must do something else. Nothing that is valuable for man can be done without passion (Weber, 2006: 91).

In our own time and context, Pérez Tamayo (1996) discusses vocation as something derived from congenital predispositions. He believes that although the concept of vocation has "real biological foundations", in the sense of genetic dispositions that endow an individual with certain abilities for certain areas, these are not the definitive factor that determines what an individual can do with his/her special gifts, since the most important historic moment is the coincidence of such required biological elements and the structure of the society in which they occur. Pérez Tamayo argues that there is no such thing as a vocation: "The youngster does not do well what he/she likes, but likes what he/she does well". That concept, he argues, reveals an excessively schematic view of reality, a simplistic outlook:

In my view, man has a much wider range of possibilities than that implied in the narrow concept of "vocation", while his professional options are strictly limited by the structure of the society and the times in which he happens to live. Many of my scientist friends could easily have been something else, but their circumstances determined that science crossed their path, and perhaps a good professor had the privilege of showing them, not only through his work but also through the example of his life, the appeal of becoming a scientist. The real test came when they conducted their first experiment and it worked well. I am sure that at that moment several or many of them decided that science was actually their "vocation" (Pérez Tamayo, 1996: s/p).

As for considering scientific work a destiny, we would have to start with the definition of "destiny" (destino) given by the Royal Spanish Academy's dictionary, which includes several definitions that we can summarize into two main meanings: 1) an unknown force believed to be the 
work of men and events. A chain of events regarded as necessary and fatal. Fate, fortune. The circumstance of an alleged way of things to happen being favorable or adverse to someone or something. Designation, appointment or application of a thing or place for a certain end. But also, 2) employment (occupation), place or establishment where someone does his/her job, and goal or point of arrival.

The combination of the two meanings ascribed to the term "destiny" plays a role in the discussion about what generates the decision to become a scientist, but it goes beyond that, because it involves the possibility of choosing and what determines it, as well as the margins of freedom and autonomy involved in the choice. This has a lot to do with the theoretical debate about how decisions are made, and even about whether any action undertaken may be called a "decision", or how much individual freedom and responsibility there is in the actions performed (Bauman, 2007). That is, one might ask how randomness, luck, an unknown fate, intervene in making it a life goal to become a scientist. Responding that it was destiny implies both setting aside one's own interests and wishes and ignoring the determining factors -many of them linked to a historic, social and cultural structure, and others being more subjective- relevant to the choice. It also means assuming oneself as incapable of agency, i.e. without any possibility of dealing with such determinations.

This discussion is also involved in understanding scientific work as a personal project, but from the opposite side, which holds that it is the subject who is the architect of his/her decisions and that he/she sets goals and achieves them through an act of will. Ciporkin (2004) explains that the concept of "project" is one of the basic notions of two twentieth century philosophers who have been relevant to the thinking about being and existence. She points out that Heidegger was the first to speak of the project as something central in the history of thought, designating it as the possibility of understanding "being", which was later adopted by Sartre in the framework of his philosophy of action. According to Sartre, "man becomes that which he himself does". From that it can be assumed that each one of the individual's actions is part of a fundamental project: the way one chooses to be in the world, expressing an original choice in specific circumstances. Simone de Beauvoir also spoke of the centrality of a personal project for women, as a way to an existence beyond the identity assigned by their role of an other in regard to men, i.e. their liberation.

The idea of a life project includes a specific temporal dimension that encompasses the past, the present, and the future, linked by a common thread and oriented towards its concretion by a will. On the other hand, interpreting a life as a project accomplished -or not-is something usually done a posteriori, when reviewing a life from a viewpoint that puts into perspective the past and the present, relating them to a final goal achieved. This has the effect of making the subject appear as aware of the path on which he/she "was placed", having the will to follow it and the ability to take some distance from it in order to analyze and understand it. According to Ciporkin, "such conceptualizations presuppose a certain human freedom regarding the possibility that this happens, as well as the intentionality and autonomy of the subject" (Ciporkin: 2004: s/p). 
Finally, assuming that one has arrived to research training as a result of a project determined by others implies placing all the weight on elements of the environment (the school system organization, the family tradition, obedience to someone else's wishes, etc.) as unavoidable conditions. In his work about the field of education, Bourdieu (1997, 2003 and 2008) pointed out that social reproduction takes place through the diversity of degrees that schools grant or cease to grant, that the modalities of inheritance are historic, and that the weight of the transmission of educational capital plays a determining role in the future that one models for oneself. But he also warned about the usual blindness that keeps us from acknowledging those determinants in the work of scholars themselves, who - partly due to their own narcissism - prefer to think of themselves as free subjects whose decisions are made strictly in the light of reason (Bourdieu, 2006).

III.

In 2001, Bourdieu (2003) wondered if scientific work was a field like any other one. He pointed out that, as in other fields, in scientific work there are particular positions and representations that give rise to pressures and operational strategies linked to an individual's position and that of others in a specific context of the field, and as a function of the information available and specific cognitive structures. Bordieu argued that an individual's strategies to operate in the field of science and his/her probabilities of success depend on the subjective position he/she occupies in the structure that constitutes that field, by which he means the structural determinations that the field has on its actors, as it happens in other fields, and the primacy of such determinations over subjective capabilities or learning. However, in order to reflect on the peculiarities of the scientific field, he asks "Which are the mechanisms that create its specificity and, at the same time, the impossibility of reducing it to the history of what is engendered there?" (Bourdieu, 2003:15). He answers this in several ways. First, he says that

The specificity of the scientific field depends, on the one hand, on the fact that the amount of accumulated history is without a doubt especially important, thanks most of all to the "preservation" of its acquisitions in a particularly economic way, e.g. through formation and formulation, or with the infinite facets of a slowly accumulated treasure of calibrated gestures and attitudes turned into habits (Bourdieu, 2003: 67-68).

This means that the field of science is the result of the accumulation of different symbolic capitals, including one that is fundamental: calibrated gestures and attitudes turned into habits. Bourdieu did not believe that scientific work was something done by an all-knowing consciousness that acted, as is often believed, according to certain explicit standards of logic and experimental work, but that it is rather a "craft": "that is, a practical sense of the problems to be addressed, some adequate ways to address them, et cetera" (Bourdieu, 2003: 73). He argues that even though the scientific field is, like other fields, a site of logical practice, it is peculiar in that, although the 
scientific habitus is also -just like in sports or in the arts- an actualized and incorporated theory, this field has the peculiarity of being a theoretical intelligence incorporated into a practical state. He points out that:

The specificity of the scientist's "craft" stems from the fact that such learning is the acquisition of extremely complex theoretical structures which are capable, on the other hand, of being mathematically formalized and formulated, and that can be acquired much faster thanks to that formalization... a double effort must be made to master that knowledge theoretically, but in such a way that it actually turns into practice in the shape of a "craft", a manual skill, a "clinical eye", and so on, and that it does not remain at the stage of a meta-discourse about the practices (Bourdieu, 2003: 75-76).

There is also the central role played in the field of science by the formalized knowledge that one seeks to master, both through the training and formulations and through the instruments (understood as the materialization of formalized knowledge). The question of the relationship between practice and method in the scientific field is seen by Bourdieu as the result of "a sense of scientific play acquired through long experience of play on the stage, with its regularities and its rules" (2003: 77). A scientist would be defined thus as "a scientific field in the shape of a man whose cognitive structures are similar to the field's structures, and who can therefore adjust continuously to the expectations inscribed in the field" (Bourdieu, 2003: 77). That is to say, there would be a structural determination relationship between the elements of the field and the subject produced within it. However, adds Bordieu, such determination is possible only because the subject determines himself through an act of knowledge and acknowledgement of the field's rules and regularities del campo, i.e. insofar as there already exists in him a certain disposition that makes him sensitive to the compulsions inherent to the field, so he will be prepared to respond to them "in a sensible fashion".

That is why, says Bourdieu, analyzing the implicit dispositions in interdisciplinary groups formed around a new object of study is an excellent way to observe and objectivize the practical ways of thinking involved in scientific practices. However, he adds, it is not easy for the subjects to put the practice, or how to acquire it, into words.

\section{IV.}

The production process of the subject of research in Mexico is an enigma if we take into account the problematic field of graduate studies in this context -the educational level at which the research training actually takes place. According to Cárdenas (2012),

Graduate programs in Mexico have problems that submerge it under the wave of globalization, endogenous problems, and problems associated with the fact that graduate studies are the last link in the chain of the educational system, and where every deficiency of the previous links comes to the surface (Cárdenas, 2012: 87). 
How have the students who reach the level of graduate studies been able to circumvent the many difficulties and deficiencies in Mexico's educational system, from the elementary levels to higher education? This seems to be due to two interconnected phenomena: on the one hand, the institutional simulation that leads to an insistence on maintaining unsustainable graduate programs, and on the other hand, the confusion between a "good student" and a researcher. Cárdenas argues that graduate programs in Mexico operate as if the students had had the education specified in the curricula of the previous levels and "attempt to strengthen something that has no solid foundations. It is the top of a crumbling pyramid" (Cárdenas, 2012: 92). She adds that

\begin{abstract}
Mexican culture has created a model of the "good student". It begins in elementary school and continues to be reproduced all the way to graduate studies... Good students want to culminate years of effort with a graduate degree. Neither the system nor the good student has a clear idea of what research entails. The system wants figures as proof of a political willingness to promote economic development, and graduate degrees are a good showcase. The good student wants to continue doing what he/she has always done. A genuine interest for knowledge and research is absent from this concert (Cárdenas, 2012: 95).
\end{abstract}

Porter (2010) argues that there is a gap between Mexico's school system and the doctorate programs that train researchers. This gap, according to Porter, exists because most of these programs have been conceived and designed based on the experience of First World countries, i.e. countries with different criteria, educational systems, and therefore students than those who graduate in Mexico, and with performance standards different from those in this country. That is why, Porter argues, the performance standards for doctorate programs in Mexico are often disproportionately high, because they are trying to compete in an international stage with researchers trained in other countries.

That is probably why graduate programs in Mexico make a great effort to produce, in spite of all their problems, a subject determined through the process of training for research, setting aside his/her background and history as a student. This effort finds an expression in thorough selection procedures, and especially in the sophisticated design of academic artifacts in which not only courses are given, seminars are offered, multiple texts and works by many authors are explored, and colloquia are held, but also there is a particularly complex device at the core of this training: an individualized direction of thesis research by research professors. Such artifacts, beyond their academic contents, ${ }^{3}$ are mediated by the design of an articulated topographical model and feature different kinds of spaces, as well as a well-organized time management and artificial performances, gestural compositions, back-and-forth trajectories (De Certeau, 2004) and, most of all, the production of a specific character: the scientific researcher.

3 How these academic programs are articulated will not be addressed here, but it would be important to learn the specific rationale that underlies their design, despite the lack of connection that we have mentioned. 
V.

Speaking about the scientific profession, Weber (2006) said that, in those times, young students had a tendency to revere certain idols in a cult founded on common knowledge: "personality" and "personal experience". According to Weber,

Both are closely linked, and there is the idea that the latter constitutes the former and is an essential part of it. People strive to "accumulate personal experiences", to promote a personality. And if this is not achieved, one must behave as if he/she had received that gift. That "personal experience" used to be called "sensation" in German, and there was a more accurate idea of the meaning of "personality". In the field of science, however, only those entirely devoted to their scientific work can have this "personality" (Weber, 2006: 94)

Thus, Weber argues that through experience we seek to shape a particular kind of personality. Following this idea, it is possible to think that training for research in our times and our context is an experience that leads directly to promote a researcher's personality. Which is that personality, and what constitutes the experience through which we seek to shape it?

As for the personality, we have already mentioned in a previous paper (Palomar, 2010) that the academic environment produces a specific subjectivity as the product of a particular culture, which is structurally determined by the type of symbolic capitals (prestige, renown, etc.) that characterize the academic and scientific field, and by the forms of power at play within that field (Bourdieu, 2008).

Who are those who constitute the academic world, and what are they like? In his work about the academic world, Bourdieu points out that these people are characterized most of all by a disproportionate narcissism that creates an illusion of self-determination. He argues that, although it is obvious that social relationships and structural determinations are prevalent in the context in which they practice their profession, scholars often see themselves as free and independent of any social coercion, which, according to Bordieu, is a product of an exaltation of their ego due to the belief that their profession makes them belong to a higher species. That ego is produced by each moment of their admission and promotion within the academic world, in their passage through its structure and its rituals, an in their repeated performance of academic practice, all of which progressively establishes a rigorous selection process that produces a privileged elite. It is an ego that would allow us to speak of the configuration of a particular character determined by the relational distribution of scholars according to their social backgrounds and connections, their political and economic resources, their academic histories, their publications, professional practices, acknowledgements and political postures, but also by the way in which the scholar participates in the institutional culture and is in turn affected by its different symbolic circuits. The scholar is also determined by the habitus generated through the daily repetition of practices pertaining to the academic world, according to the mental structures that turn it into a familiar and self-evident universe in its social 
determinations and in the rules that regulate its internal operation at every level. Those mental structures include other functions, such as the discernment used for the classifying acts and their products, which rules out understanding discernment as a conscious or random intellectual act, since it is understood as one of the expressions of a previously shaped mental structure, and of the enactment of the habitus (Bourdieu, 2013: 15). Thus, how we classify already expresses different or opposite positions involved in the social space of academia and research.

Regarding the experience of research training, we may argue that it is formed basically by two mechanisms pointed out by Bordieu (1997): familiar strategies and the rationale of educational institutions. Guichard (1995) has said that the experience of school stimulates in students a specific kind of intentions about their future, and that those intentions may turn into either projects or a complete lack of a temporal perspective about a project. This leads the youth, according to Guichard, to generate a given type of representations of the future depending on how his/her experience of school has been $v i s-\grave{a}$-vis what he/she knows, learns, and is able to do.

Nevertheless, it must be taken into account that the experience is not out there in reality, empty and awaiting a previously existent subject; rather, we argue that the subject is shaped in the experience as an effect of the discourse of science, the culture of institutions, and the specific practices involved in the training of the new researchers in each program. All these elements come into play with the factors in the social and cultural context of the subject (Scott, 2001), and when they come together they produce specific particular subjective configurations that determine, for instance, how links to academic culture are established, or how a particular lifestyle is chosen according to the class habitus -ways of behaving, tastes, attitudes, ways to see and feel-as well as to the gender, age group and cultural context to which he/she belongs. From this perspective, we may argue that the research training experience produces a character whose personality will have traits that incorporate the determinations that have played a role in individual histories, the forces of the academic and scientific field, an a sort of common professional identity core. ${ }^{4}$

De Laurentis (1992) argues that experience is the result of hermeneutic work linked to the self-representation process that defines the ego. Through this process, the subject interprets reality and locates himself in it based on notions that have been incorporated unconsciously and that lead him to take a position and act in a certain way in the world. Bauman (2007), in turn, points out that experience comes "pre-packaged, pre-interpreted"; i.e. that the experience takes place within a context of certain common sense beliefs that make what has been experienced intelligible through a particular, previously installed modality. From this viewpoint, research training is a realm in which, at the same time as people go through a predetermined experience, a particular character, whose personality is a reflection of the complexity of a scientific-academic field crisscrossed by the tensions of its social, economic and political environment, is produced.

4 The identity shape adopted by the subjects of the academic world, argues Dubar, is directed more towards the "realization of the self" and to seek "personal fulfillment", according to the current individualization process (Beck, 2003) and meritocracy mechanisms aimed at rewarding individual actions in a very competitive environment that ignores subjective differences and the uncertainty typical of scientific work, as well as an ever growing job insecurity which there are desperate attempts to invest with some kind of meaning (Dubar, 2002: 148). 
VI.

With this conceptual framework, we decided to take advantage of an opportunity to make a simple exploration of the process that produces the subject of research from the viewpoint of the students of some training programs. The objectives of this exploration were: 1) to understand what leads a student to be trained as a researcher; 2) to learn about the experience of training for research, and 3) to obtain an outline of the representation that these students build of the craft and the subject of research. ${ }^{4}$

The sample for this study consisted of students from four different graduate research training programs: two doctorate programs and two generations of the same masters' degree program. A random selection from the attendance list of the groups was used to obtain the sample, and those who were selected were invited to participate in it through an e-mail message. Finally, the sample was composed of eleven students who were invited and agreed to participate within a specific time frame: four doctorate program students and seven from masters' degree programs, five of them female and six male. They were sent a questionnaire by e-mail, with fifteen items linked by five previously established analytical categories:

1. Motives involved in the decision to learn the research craft.

2. The experience of learning the craft (moments, events, things learned, decisions, etc.) and judgments about the training program.

3. Definition of the research craft (norms, values, rules, habits, adjectives associated with it, etc.) and changes originated by the program in previous ideas about it.

4. Descriptions of the professors and thesis directors, and of the relationship established with them.

5. The ideal researcher (traits, models, success).

The answers were also received via e-mail. This was followed by the organization and processing of the data, which were first analyzed individually. The answers to each item were then grouped together to make a transversal analysis of the information. Finally, the findings were connected to the analytical categories in order to interpret the information.

VII.

In a very brief way and in an effort to draw some points as conclusions from the data obtained in the study, we will now attempt to reflect upon the questions presented at the beginning of this paper, and discuss our first claims.

Our data show that, for those who answered our questionnaire, "destiny" was the factor that appeared more clearly as decisive in being in a research training program. Following Pérez Tama-

5 The study had very clear and precise constraints, derived first of all from the fact that there was very little time to conduct it, since we were trying to explore some hypotheses originated in daily work and present them in a seminar that was about to be held on this issue. The students were about to finish a cycle and go on vacations, and some were about to finish their program. In this context, I followed an impulse to take advantage of the opportunity, accepting the implications. Nevertheless, I also believe that the brief information obtained constitutes a corpus of significant data that allows us to reflect on some issues and clarify some ideas for future, more in-depth research. 
yo, it seems that for these students science "crossed their path" as a possible road and they just followed it. One of the subjects, in fact, makes a clear reference to "the random ways of fate" that intervened in having undertaken a research graduate program. But other students speak of other interests relating to their professional studies, such as searching for solutions to concrete problems, trying to take some distance for their everyday job, or earning the degree or specialization. Even though this does not show a specific choice to do scientific work, it does seem to be linked to an idea of a life project deliberately planned in the long term. At this point, it is important to mention the relevance that earning a graduate degree has acquired for those who are already working in an academic environment - many times as teachers - as a way to ensure not only job security, but also upward mobility in the wage scale, which means not only getting a higher salary, but also better conditions for retirement. Although none of the students who answered the questionnaire mentioned this factor explicitly, it is highly likely that behind the desire to "earn the degree" or "get the specialization" - which were mentioned - is this element, rather than a vocation or a genuine interest in science. In the references to a desire to "be trained in research", seen as an "area full of life and work" that leads to "advancement, improvement, credibility" and that is "very gratifying" is where we might perhaps see some signs of such an interest.

On the other hand, it seems that the students who answered the questionnaire see themselves as controlling their own decisions and able to articulate a life project that, with the help of their willpower and other virtues, will lead them to earn a degree. There is no attempt at reflecting on the factors that weighed on their decision, other than their own volition and judgment. Earning the degree seems to be the goal intended when joining the training program, rather than learning to do research.

As for how the students who answered the questionnaire define the research craft, it is striking how imprecise their ideas about research are, which probably has something to do with how unclear the program itself is about what doing research entails. For instance, there was no mention of an interest in knowledge or systematic inquiry, or in understanding or explaining reality. This leads us to agree with Cárdenas (2012), who argues that graduate students seem to function on the belief that in order to be a good researcher it is enough to be a good student, which is defined as being obedient and submissive to an academic system rather than by a critical and inquiring spirit, which should be a researcher's defining characteristic.

In the answers of the students who were part of this sample we can observe that among the "things learned" reported are the acquisition of complex theoretical constructions, albeit in a quick and condensed fashion, as well as the effort to transfer the knowledge learned to the practice in the shape of a "craft", through the development of methodological, technical and manual skills, intuition, and a "clinical eye". However, if we take into account the fact that the research training program must dedicate a lot of time to cover deficiencies in the basic education of most of the students (use of spoken and written language, text comprehension and analysis, logical thought, a broader 
cultural background, among others), as well as the constraints of time and financial support, it becomes clear that the "things learned" will not be comprehensive enough, nor deep enough, to generate a really effective habitus for research, which should be the result of research training programs.

Among the different spaces and moments that constitute the training process, students distinguish especially two: one, the work with their thesis director, and two, the research colloquia. About the first one, we may say that it is a space seen as a site of transmission of something more experiential than rational about research, favored by the rapport achieved with the research professor. About the second, it is worth noting that, while colloquia are described as stressing and unpleasant experiences, it is also said that they "are good". This way of speaking about them leads one to think of them as a necessary evil, something painful but formative, a suffering that nevertheless bring about fruitful results. This experience of colloquia confirms our notion that the links between scientific and religious training are still close. Suffering through the colloquia with a resignation derived from the conviction that they are helpful and formative, no matter how unpleasant and stressing they might be, reminds us inevitably of the value given to suffering by Christians: something that seems to be linked to misdeeds and sin (i.e. it is deserved), but also a very formative experience because, among other things, suffering enlightens consciousness about the sins committed, teaches humility, and warns against hubris. It also allows people to learn obedience and self-control, which are purifying and rewarded.

Based on the data analyzed, we may conclude that research training programs operate as artifacts for the production of a certain kind of subjectivity embodied in a certain kind of person. These artifacts might be regarded, following Foucault, as "technologies of the Self", insofar as this training

allows individuals to make, by themselves or with the help of others, a number of operations on their body and soul, thoughts, behavior, or any form of being, thus obtaining a transformation of themselves in order to achieve a certain state of happiness, purity, wisdom, or immortality (Foucault, 1990: 48).

The research training program device produces a particular character who is topologically organized and whose goal is then not only academic learning. This training starts from a no-where -that of the layman - from which the apprentice must embark on a journey -training- with a precise final destination - the degree examination, which will endow the subject with his/her identity as a researcher. This means that, besides promoting certain learning or a change in behavior, attitude, status, and way of life, such training also leads to changes in self-perception and in the subject's own identity. Research training appears then as a process produced by a lay device to train not only the intellect, but also the feelings and the senses, in a sort of asceticism on the path to knowledge. ${ }^{6}$

6 We use the word "lay" to distinguish it from religious devices that may be very similar to those of research training (as is the case of Ignacio de Loyola's Spiritual Exercises of which Barthes [2010] speaks), as technologies for the production of a specific and sought subjectivity. 
It is, in short, about learning to submit one's life to a given order and to model one's own subjectivity according to certain guidelines so both are adapted to the ideal of science and, through this, one attains a place in the order of knowledge.

Research training programs lead students, through implied discourses and knowledge, their topological and chronotopical organization, the ways of doing (De Certeau, 2000) of research professors and thesis directors, to conduct a number of operations on themselves, with the promise that they will thus manage to become the ideal researcher. Which are those operations and which is that ideal? Among the operations that students need to conduct on themselves are (and this is not an exhaustive list): organizing their daily life rhythms around the needs of the training, a rational distribution of the time required for the others and for personal activities, the need to simulate the economic interests involved in research, the delimitation of the spaces destined for movement and bodily pleasures, the formulation of new ethical codes and scales of values around the priority of academic and research work, the stifling of emotional expression or aspects of sentimental or personal life and their subordination to the needs of the training program, the development of a stoic acceptance of criticism accepted as a necessary "formative element" of the professional Self, the establishment of a personal -"intimate", some would say, and not very clear in its nature- link with the thesis director, in which the most subtle transmission of the research craft takes place, not just as a what to do but as a what to be, i.e. a subjectivity encompassed by a professional practice, all of this interwoven with an affective dimension that may act either as a facilitator or as the worst obstacle in the training of the new researcher, because this element is often overloaded with expectations and an intense affective transference that is never analyzed or solved.

Thus, the training of researchers is not limited to the conscious learning of theoretical, methodological or disciplinary contents, nor to a more or less conscious incorporation of a habitus pertaining to the craft of research. We have seen that there is another important level in this training: the day-to-day experience of the academic culture of the graduate program created by a body of research professors in their interaction with their students and their peers, which involves community practices, discourses, customs and rituals that generate specific structures of meaning, as well as the implicit formulation of professional identity codes and certain ways of doing that are transmitted through both behavior and words. Along this path, research apprentices are introduced to a particular world of meanings, and to a shared symbolic system composed of certain ways of living and working together (Bruner, 2006), which is closely linked to the norms, ideals, values and symbolic goods regarded as belonging to the academic world in which they work. This world condensates two main registers: that of the ideal scientific discourse, and that of the daily institutional reality. The confluence of both discourses produces a discursive figure that is perhaps the central piece in the production of a subjective configuration whose achievement is sought through the training processes of the new researchers. 
Following Bourdieu's ideas that the powers associated with the teaching system are not exercised without the active complicity of those who impose or suffer them, we argue that the transmission of the ideal of the researcher as a power mechanism of the research training device shows its effectiveness as it becomes evident in the classifications that students apply to their professors or thesis directors, insofar as the schemes they use to classify them are the result of having incorporated a habitus linked to the power that such an ideal generates to transform the students' subjectivity. It is a mystification of research work and its perverse effects, since the construction of a glorified image of research work and of themselves as researchers, far from being a formative element, prevents them from concentrating on the correct performance of their work (Cárdenas, 2012).

Bourdieu defined a scientist as "a scientific field embodied in a man whose cognitive structures are homologous to the structure of the field and, for that reason, adjust themselves continuously to the expectations inscribed in the field" (Bourdieu, 2003). Based on the information obtained in our study, we may conclude that researchers who complete research training graduate programs show that they are indeed "a field embodied in a man", but not necessarily a scientific field: rather, an institutional academic field regulated by specific cultural, economic, and political rules. That is, if there is a structural determination relationship between the elements pertaining to the field and the subject who inhabits it, the subject trained in the research training programs is a character whose disposition makes him/her sensitive to those rules, which are consubstantial to the field of the determining power. Indeed, we could argue that the motivations to learn the research craft captured in this research are expressions of the previous disposition to participate in this field and of the sensitivity to the commination involved in it, which enable the subjects to be "good students" in the sense that they will follow and meet the requirements and demands of the training, and not critical, questioning students with a passion for knowledge.

We found that the students who answered the questionnaire imagine themselves practicing the research craft based strictly on what they know: automatic advancement to the next educational level, "completing" their work as teachers, following the institutional norms they know, working in a team, and with institutional tenure as a researcher. In their predictions, however, the subjects glimpse an optimistic future that will allow them to be what the program offers them in terms of character building and skills, and be able to work in known institutions. There is no hint of foresight of any difficulty to find a job or inability to practice the craft, so they do not explore new alternatives or horizons, and much less any discussion of the possibility of transforming the order that prevails in the institutional field of science.

Finally, we could see that the students who answered the questionnaire associate the researchers' success mostly to individual personal qualities and not to anything related to their career, their scientific training, or the results obtained by their research. That is, a program's success will be demonstrated if it achieves what its objectives state: to create "human resources" of "high quality and excellence". If the graduate program alumni are held in such regard, that would explain 
the arrogance and narcissism often displayed by researchers since, as Latapí (2007) pointed out, the idea of excellence entails the illusion of perfection. It makes sense to wonder, then, if what is expected of a research training program is to achieve excellence rather than to learn how to do research.

In a time when one's ego, one's image, and the prestige and recognition given to one's person seem to be paramount, it is easy to mistake which is the center of the research craft. Is it the researcher, his/her personality and identity, or the research work he/she conducts? Would it not be better to view the subject of science as a position in the whole of formal relationships defined by the scientific environment itself, and not as a character on the stage of identity politics? From that perspective, the center of importance would be on what is produced by occupying the scientific position, not on the character who occupies it. However, in the present context, in which science is increasingly viewed as a commodity and a private property, the scientist's personality is regarded as something so important that it is believed that it is the personality which gives value to the work, not the other way around.

To summarize, we may say that, although the ever growing production of graduates from graduate research training programs seems to be beneficial for Mexico's image -since it generates indicators that justify making a financial investment in the sector of science and technology, and contributes to the production of an imaginary of modernity and national development required to take part in the concert of nations- the gap between Mexico's higher education and the level required to do research -which is dramatically evident in graduate programs- leads both to an irrational, overly demanding selection and training of research apprentices, and to the paradoxical indulgence of professors and administrators about the limitations they face in the classroom, which translates into the sickening "you will not fail" or the previous "you will not notice" what is happening, in order to continue meeting success rates that guarantee budgets, positions, prestige, and stability. All of the above contributes also to produce the "evidence" of a supposed success of Mexico's educational system and optimal institutional performance. The result is the production of more and more generations, more and more numerous, of younger and younger researchers with, nevertheless, fewer and fewer opportunities of finding spaces to do research in the terms in which they have been trained.

\section{References}

Barthes, Roland (2010). Sade, Loyola, Fourier. Madrid: Cátedra.

Bauman, Zygmunt (2007). Libertad. Buenos Aires: Losada.

Beck, Ulrich and Elisabeth Beck-Gernsheim (2003). La individualización. El individualismo institucionalizado y sus consecuencias sociales y políticas. Barcelona: Paidós. 
Bourdieu, Pierre (1997). Capital cultural, escuela y espacio social. Mexico: Siglo XXI.

— (2003). El oficio de científico. Ciencia de la ciencia y reflexividad. Barcelona: Anagrama. and J. C. Passeron (2003). Los herederos. Los estudiantes y la cultura. Buenos Aires: Siglo XXI.

- (2006). Autoanálisis de un sociólogo. Barcelona: Argumentos. (2008). Homo academicus. Argentina: Siglo XXI. (2013). La nobleza del estado. Buenos Aires: Siglo XXI.

Bruner, Jerome (2006). Actos de significado. Más allá de la revolución cognitiva. Madrid: Alianza editorial.

Cárdenas, Cristina (2012). "El posgrado en el conjunto del sistema educativo mexicano". In Chavoya Peña, María Luisa and Sonia Reynaga Obregon (coords.). Diversas miradas sobre los posgrados en México. Mexico: Universidad de Guadalajara, pp. 85-106.

Ciporkin, Martha Beatriza (2004). “¿Vocación o destino?”. In Revista electrónica de psicología politica. Year 2, No. 6, June 2004. San Luis, Argentina. Available at http://www.psicopol.unsl. edu.ar/junio04_nota1.htm [Consulted: 06/10/2015]

De Certeau, Michel (2000). La invención de lo cotidiano 1. Artes de hacer. Mexico: Universidad Iberoamericana/ITESO.

(2004). "El espacio del deseo". In Arte y espiritualidad jesuitas. Principio y fundamento. México: Artes de México, No. 70, pp. 39-47.

De Laurentis, Teresa (1992). Alicia ya no. Feminismo, Semiótica, Cine. Madrid: Cátedra.

Dubar, Claude (2002). La crisis de las identidades. Barcelona: Bellaterra.

Foucault, Michel (1990). Tecnologías del yo y otros textos afines. Barcelona: Paidós/I.C.E.-A.A.B.

Guichard, J. (1995). La escuela y las representaciones de futuro de los adolescentes. Barcelona: Laertes.

Latapí Sarre, Pablo (2007). Photocopied excerpts of the Magisterial Lecture given upon receiving a Honoris Causa Doctorate from Universidad Autónoma Metropolitana on February 22, 2007 in Mexico City. Mexico.

Noble, David F. (1993). A World Without Women: The Christian Clerical Culture of Western Science. Oxford: Oxford University Press.

Palomar, Cristina (2010). "Género y subjetividad en el mundo académico". In Chavoya Peña, María Luisa and María Guadalupe Moreno Bayardo (coords.). Temas selectos de la investigación educativa en Jalisco. Mexico: Universidad de Guadalajara.

Pérez Tamayo, Ruy (1996). "La vocación científica". In Acerca de Minerva. Mexico: Fondo de Cultura Económica. Available at http://bibliotecadigital.ilce.edu.mx/sites/ciencia/volumen1/ ciencia $2 / 40 / \mathrm{htm} / \mathrm{sec} \_29 . \mathrm{html}$ 
Porter, Luis (2010). "Prólogo". In Moreno Bayardo, Ma. Guadalupe (2010). Historias de formación para la investigación en doctorados en educación. Mexico: UdeG/Coecytjal/Plaza y Valdés.

Real Academia Española (RAE), Online dictionary at http://www.rae.es/recursos/diccionarios/drae

Scott, Joan (2001). "Experiencia”. In La ventana. Revista de estudios de género. Vol. II, núm. 13. Julio, 2001. Guadalajara: Universidad de Guadalajara, pp. 42-74.

Weber, Max (2006). Política y ciencia. Buenos Aires: Leviatán. 